\title{
Fresh semen characteristics in captive accipitrid and falconid birds of prey
}

\author{
Vladimir Piacek ${ }^{1}$, Jan Zukal², Veronika Seidlova ${ }^{1}$, Tomas Heger ${ }^{1}$, Monika Nemcova ${ }^{1}$, \\ Michal Pribyl $^{1}$, Frantisek Vitula ${ }^{1}$, Jiri Pikula ${ }^{1}$ \\ ${ }^{1}$ University of Veterinary and Pharmaceutical Sciences Brno, Faculty of Veterinary Hygiene and Ecology, \\ Department of Ecology and Diseases of Zoo Animals, Game, Fish and Bees, Brno, Czech Republic \\ ${ }^{2}$ Academy of Sciences of the Czech Republic, Institute of Vertebrate Biology, Brno, Czech Republic
}

Received April 21, 2020

Accepted June 22, 2020

\begin{abstract}
Artificial insemination (AI) is the most frequently used assisted reproductive technique for captive propagation of rare avian species. As semen quality is critical for reproductive success, baseline data are needed for evaluating and selecting the best male bird donors. To this end, we used computer-assisted semen analysis to assess male eastern imperial eagles $(n=7)$, northern goshawks $(n=24)$ and peregrine falcons $(n=20)$. While imperial eagles and northern goshawks donate ejaculate voluntarily, peregrine falcons required cloacal massage. Eight peregrine falcon females were inseminated with semen from eight males, with fresh ejaculates (15 to $50 \mu 1)$ applied to the pars uterina of the oviduct immediately after collection and examination. All females were inseminated within $2 \mathrm{~h}$ of laying an egg. A fertilization rate of $70 \%$ was achieved using this method. Minimum semen characteristics associated with egg fertilization included a semen concentration of $115.12 \times 10^{6} / \mathrm{ml}, 33.52 \%$ total motility, $1.92 \%$ spermatozoa with progressive motility and $0.17 \%$ with rapid motility. Comparative data on spermatozoa concentration and kinematics suggest that eastern imperial eagles concentrate on high quality semen investment at the start of the breeding season, northern goshawks compensate for a decrease in motilityassociated parameters with increased semen concentration and peregrine falcons maintain semen production standards throughout the breeding season. Our data show that, in birds of prey, levels of egg fertilization following AI with fresh semen can be almost as successful as after natural mating.
\end{abstract}

Raptors, ejaculate quality, artificial insemination, fertilization rate, endangered avian species conservation

Despite some limitations, captive propagation is an essential ex situ strategy for breeding birds of prey, whether for endangered species conservation or falconry purposes (Snyder et al. 1996; Bailey and Lierz 2017). Indeed, such methods have proved important for the recovery of wild populations of critically endangered and charismatic species, such as the Californian condor (Meretsky et al. 2000), peregrine falcon (Fleming et al. 2011) and Mauritius kestrel (Jones et al. 1995). In addition to loss of habitat and resources and over-exploitation, declines in these species are frequently associated with environmental pollutants that induce deleterious effects on avian reproduction (Fry 1995; Pikula et al. 2013; Hruba et al. 2019). Furthermore, as the number of captive-bred birds of prey increases, the international demand on birds for the falconry trade has been saturated, with native species benefiting from a drop in illegal capture of wild birds.

In captivity, birds of prey are either allowed to mate naturally or are subjected to assisted reproduction (Bailey and Lierz 2017). To prevent failures in breeding projects, a good knowledge of reproductive physiology is necessary in order to ensure breeding pair quality and general state of health, species-specific differences, male and female synchronization, sperm characteristics, fertilization processes, egg formation, laying cycle and fertilized egg incubation. The most common assisted reproductive technique utilised in birds of prey is artificial insemination (AI) using fresh semen, or semen after no more than two days of 
storage in a refrigerator at $5{ }^{\circ} \mathrm{C}$. Imprinted males are either trained to donate ejaculate or semen is collected by forced massage (Bailey and Lierz 2017).

While assisted reproductive techniques are combined with cryopreservation in mammals (Fickel et al. 2007), cryogenic storage of avian semen is still a problem due to physiological sensitivity and poor survival of sperm, with use of sperm undergoing a freeze/thaw cycle resulting in highly variable fertility rates (Samour 2004; Long 2006). Much research is still needed in order to obtain data on physiological semen quality parameters relevant for testing appropriate techniques on rare avian species and for developing reliable protocols applicable for cryopreservation.

The present study uses computer-assisted semen analysis (CASA) for assessing semen collected from the eastern imperial eagle (Aquila heliaca), northern goshawk (Accipiter gentilis) and peregrine falcon (Falco peregrinus). Quantitative CASA measurements were used to compare spermatological values in the three species and to test predictions of species-specific differences reflecting the mating systems of the species examined, breeding season length and male and female synchrony.

\section{Materials and Methods}

Male birds and their state of health

Samples for the present study were obtained from captive male eastern imperial eagles $(n=7)$, northern goshawks $(n=24)$ and peregrine falcons $(n=20)$ during medical and reproductive assistance services to private falconers. All birds were 5 to 6 years old.

Prior to the reproductive period, the birds were subjected to a thorough clinical examination, including blood chemistry and haematology. Blood $(150 \mu \mathrm{l})$ was collected from the right jugular vein using a heparinised $1 \mathrm{ml}$ 30 G $1 / 2$-in Omnican syringe (B. Brown Injekt ${ }^{\mathbb{}}$, Germany). Standard blood indices were evaluated using Avian/ Reptilian Profile and EC8+ diagnostic cartridges in VetScan VS2 and i-STAT analysers (Abaxis, Union City, CA, USA), respectively. A cloacal swab was collected for microbiological culture in order to exclude presence of pathogenic microorganisms in the alimentary and/or urogenital system. Parasitological examination of faeces was performed using the flotation method. Only healthy, parasite-free males showing non-pathogenic microflora were used for subsequent semen collection.

\section{Semen collection}

While imperial eagles and northern goshawks donated their ejaculate voluntarily, samples from peregrine falcons were collected via cloacal massage (Gee et al. 2004). A total of 51 semen samples (imperial eagles $n=7$, northern goshawks $n=24$, peregrine falcons $n=20$ ) were collected into $100 \mu$ l uncoated glass capillary tubes (Keraglass a.s., Otvovice, Czech Republic).

\section{Semen quality}

In all cases, care was taken to avoid sperm contact with water and prevent exposure to direct sunlight and/ or temperatures outside the range of $19-21{ }^{\circ} \mathrm{C}$. Immediately after collection, fresh semen characteristics were determined using a Sperm Class Analyser - Computer Assisted Sperm Analysis (SCA CASA) system (MICROPTIC S.L., Barcelona, Spain), with concentration and motility determination modules and a Nikon eclipse E200LED MV R camera equipped with a Nikon $10 \times 0.25$ Ph 1 BM WD 7.0 lens (NICON CORPORATION, Tokyo, Japan) and an acA 1300-200uc Basler c-Mount camera (BASLER AG, Ahrensburg, Germany). Semen concentration $\left(\times 10^{6} / \mathrm{ml}\right)$ and total motility parameters were measured in a counting chamber Leja SC 20-01-08-B-CE (CRYO TECH s.r.o., Liběchov, Czech Republic) of $8 \times 2 \mu 1$ volume. The fresh semen characteristics assessed included percentage of spermatozoa showing progressive and non-progressive motility and immotility, the velocity percentage of spermatozoa with rapid $(>100 \mu \mathrm{m} / \mathrm{s})$, medium $(50 \mu \mathrm{m} / \mathrm{s})$ and slow $(<10 \mu \mathrm{m} / \mathrm{s})$ motility and the percentage of rapid and medium progressive and non-progressive spermatozoa. Progressive motility refers to spermatozoa that are mostly swimming in a straight line or in very large circles, while non-progressive motility refers to spermatozoa that move but do not make forward progression in straight lines or by swimming in very tight circles.

\section{Artificial insemination using fresh semen}

Semen collected from eight male peregrine falcons and examined for semen characteristics was used to inseminate eight females exhibiting reproductive behaviour (e.g. vocalization and nest making in early February). The females were inseminated using a Discovery Comfort 1-250 $\mu$ pipette (BIOTECH innovative, Prague, Czech Republic) within $2 \mathrm{~h}$ of laying the previous egg. The insemination dose contained fresh semen and was used immediately after collection, the ejaculate volume applied to the oviduct pars uterina ranging from 15 to $50 \mu 1$.

The insemination procedure was carried out as quickly as possible in order to reduce stress to the female. 
Statistical analysis

Four samples (two from northern goshawk, two from peregrine falcon) were excluded from the statistical analysis owing to extreme differences in fresh sperm motility parameters. Normality was then tested for each species' data subset using Kolmogorov-Smirnov and Shapiro-Wilk tests. Sperm concentration per ml displayed normal distribution and was not transformed. Motility parameters were arcsine transformed to represent the inverse sine of the square root of the proportion, the results of transformation being expressed in radians. The relative date of sampling was calculated with March as the first designated value (1), this being used as an independent variable for the Pearson correlation coefficient. Subsequently, the breeding season for semen sampling was divided into two sub-periods for each species (Table 1). Differences between species and semen sampling sub-periods were tested using factorial ANOVA with Bonferroni correction, with the probability value set at $P=0.005$. Interaction between both parameters was included into the model. Semen samples that resulted in egg fertilization were compared with non-fertilizing samples using one-way analysis of variance (ANOVA) and Kruskal-Wallis test.

Table 1. Times of semen sampling.

\begin{tabular}{lccc}
\hline Species & Date of the first sampling & Date of the last sampling & Duration of the sampling period (days) \\
\hline Aquila heliaca & March $25^{\text {th }}$ & April $4^{\text {th }}$ & 11 \\
Accipiter gentilis & April $1^{\text {st }}$ & April $24^{\text {th }}$ & 24 \\
Falco peregrinus & March $\left(11^{\text {th }}\right)^{* 23^{\text {th }}}$ & April $16^{\text {th }}$ & 25 \\
\hline
\end{tabular}

* Two samples of Falco peregrinus obtained on March $11^{\text {th }}$ were excluded from the analysis.

\section{Results}

While semen concentration showed a significant positive correlation with the date of sampling $(\mathrm{r}=0.56 ; P=0.005)$ in the northern goshawk (Fig. 1A), there was a non-significant decline during the breeding season in the other two species examined. Despite this, there was no significant difference between the three species as peregrine falcon semen concentration was highly variable during the first sub-period (Fig. 1B). Similarly, there was no significant difference between the overall percentage of motile or immotile spermatozoa between the species or the sampling period (Table 2). Significant differences were only observed for four parameters related to progressive motility, i.e. percentage of spermatozoa showing progressive motility, percentage of spermatozoa with rapid motility, and percentage of rapid and medium progressive spermatozoa. The data on semen quality (Table 3) indicated that the three species utilized different timing strategies for sperm production (Fig. 2).

Table 2. Results of factorial analysis of variance (ANOVA) of fresh semen variables.

\begin{tabular}{lrrrrrrrr}
\hline $\begin{array}{l}\text { Arcsin-transformed } \\
\text { semen variables }\end{array}$ & SS Model & df Model & MS Model & SS Residual & df Residual & MS Residual & F & $P$ \\
\hline Concentration* & 78715.59 & 5 & 15743.12 & 241740.4 & 45 & 5372.01 & 2.93 & 0.02 \\
PR & 0.70 & 5 & 0.14 & 1.0 & 45 & 0.02 & 6.09 & $<\mathbf{0 . 0 0 1}$ \\
NP & 0.29 & 5 & 0.06 & 1.9 & 45 & 0.04 & 1.34 & 0.26 \\
IM & 0.62 & 5 & 0.12 & 3.1 & 45 & 0.07 & 1.78 & 0.14 \\
Motile & 0.61 & 5 & 0.12 & 3.1 & 45 & 0.07 & 1.77 & 0.14 \\
Velocity/r & 0.80 & 5 & 0.16 & 0.7 & 45 & 0.02 & 9.75 & $<\mathbf{0 . 0 0 1}$ \\
Velocity/M & 0.31 & 5 & 0.06 & 0.8 & 45 & 0.02 & 3.29 & 0.01 \\
Velocity/S & 0.61 & 5 & 0.12 & 1.7 & 45 & 0.04 & 3.27 & 0.01 \\
VP/R & 0.14 & 5 & 0.03 & 0.3 & 45 & 0.01 & 4.78 & $\mathbf{0 . 0 0 1}$ \\
VP/M & 0.54 & 5 & 0.11 & 0.8 & 45 & 0.02 & 5.96 & $<\mathbf{0 . 0 0 1}$ \\
\hline
\end{tabular}

*Concentration was normally distributed and was not transformed; PR = percentage of spermatozoa with progressive motility; $\mathrm{NP}$ = percentage of spermatozoa with non-progressive motility; IM = percentage of immotile spermatozoa; Motile = percentage of motile spermatozoa; Velocity/R = percentage of rapid velocity spermatozoa $(>100 \mu \mathrm{m} / \mathrm{s}) ;$ Velocity $/ \mathrm{M}=$ percentage of medium velocity spermatozoa $(50 \mu \mathrm{m} / \mathrm{s})$; Velocity/S = percentage of slow velocity spermatozoa $(<10 \mu \mathrm{m} / \mathrm{s}), \mathrm{VP} / \mathrm{R}=$ percentage of rapid progressive spermatozoa; $\mathrm{VP} / \mathrm{M}=$ percentage of medium progressive spermatozoa. 

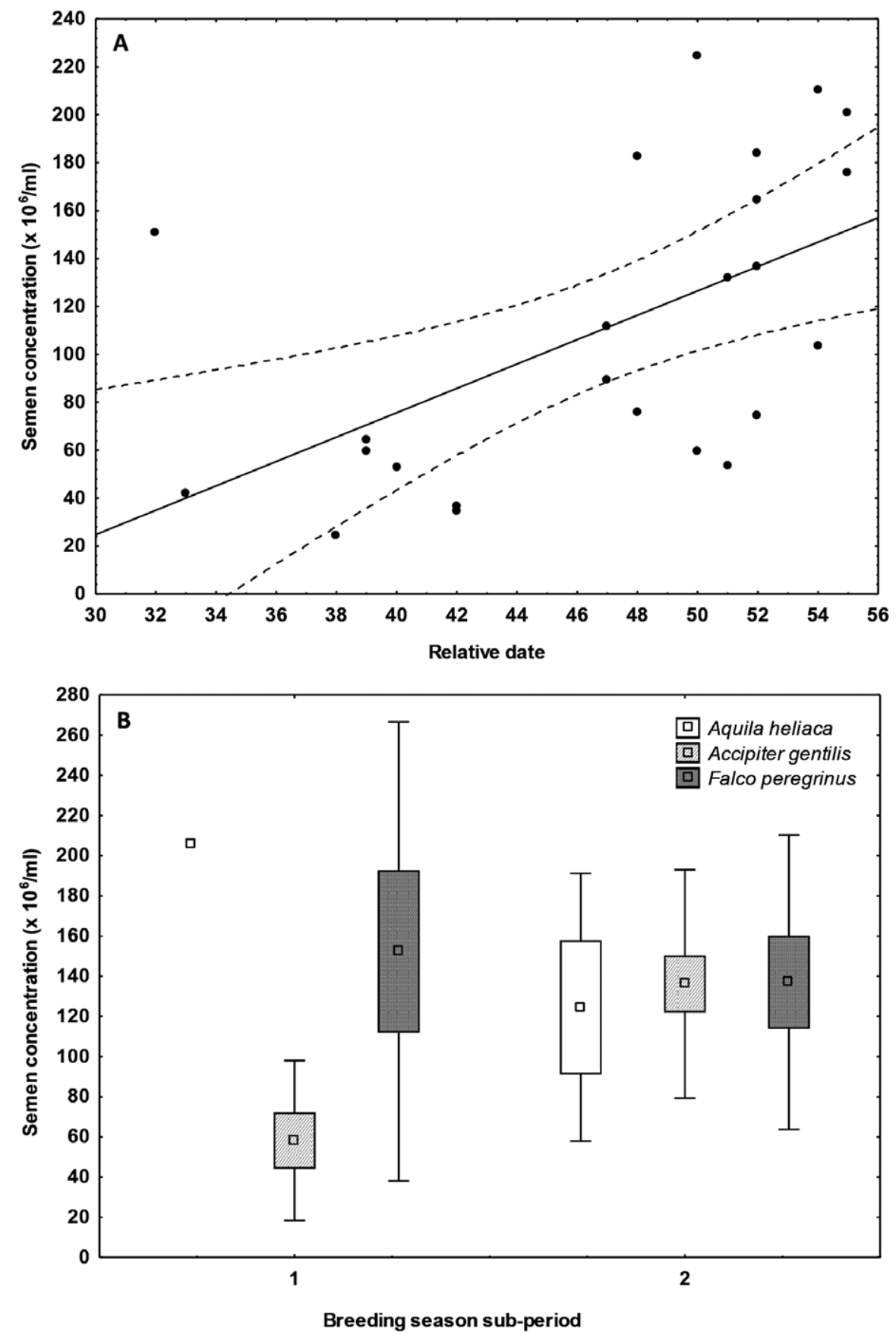

Fig. 1. Correlation of Accipiter gentilis semen concentration (A) with relative breeding season sampling date and (B) box-plots for particular breeding season sub-periods. Explanation: central point $=$ mean, box $=$ standard error, whisker $=$ standard deviation, outliers excluded. 

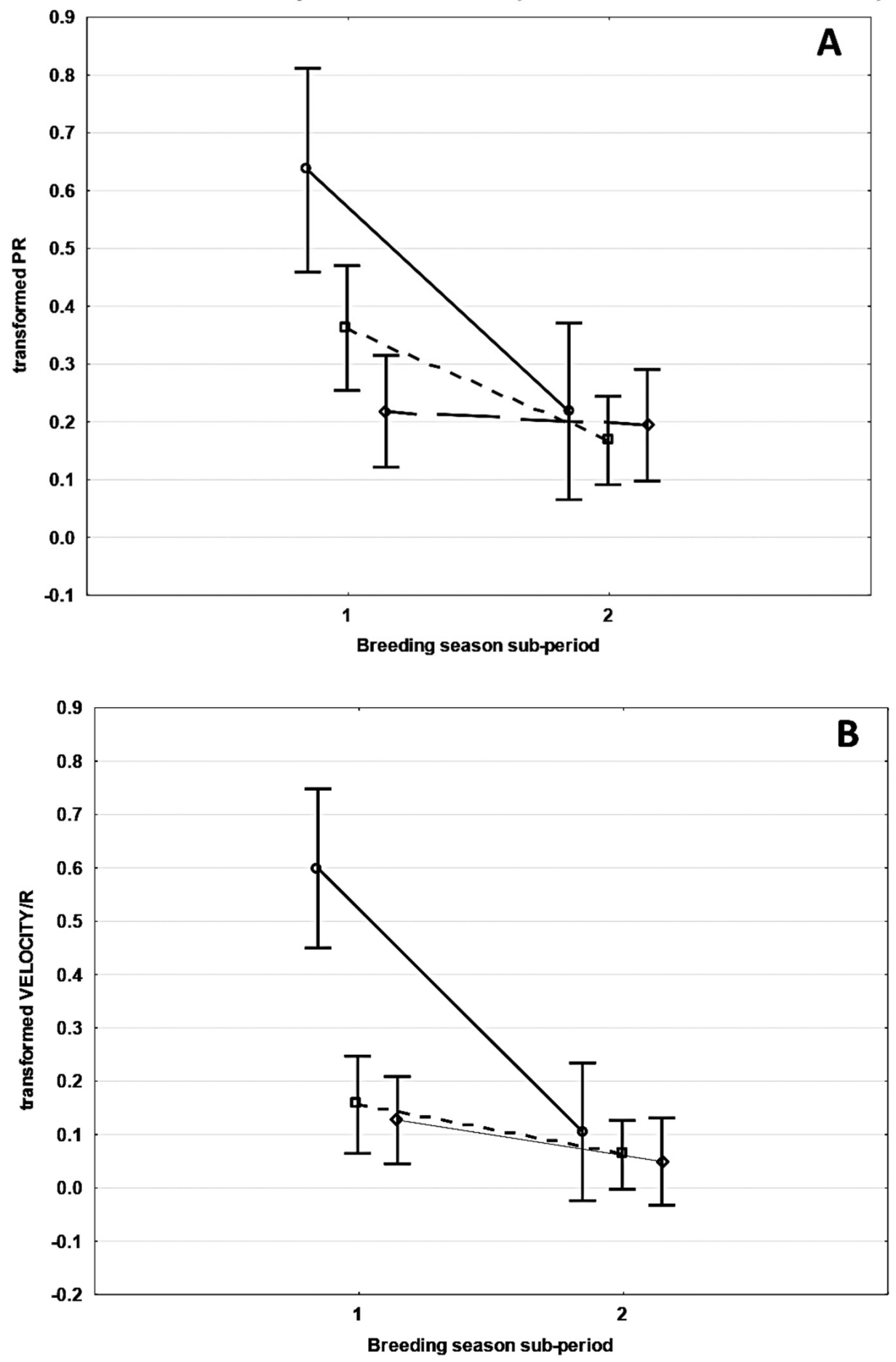

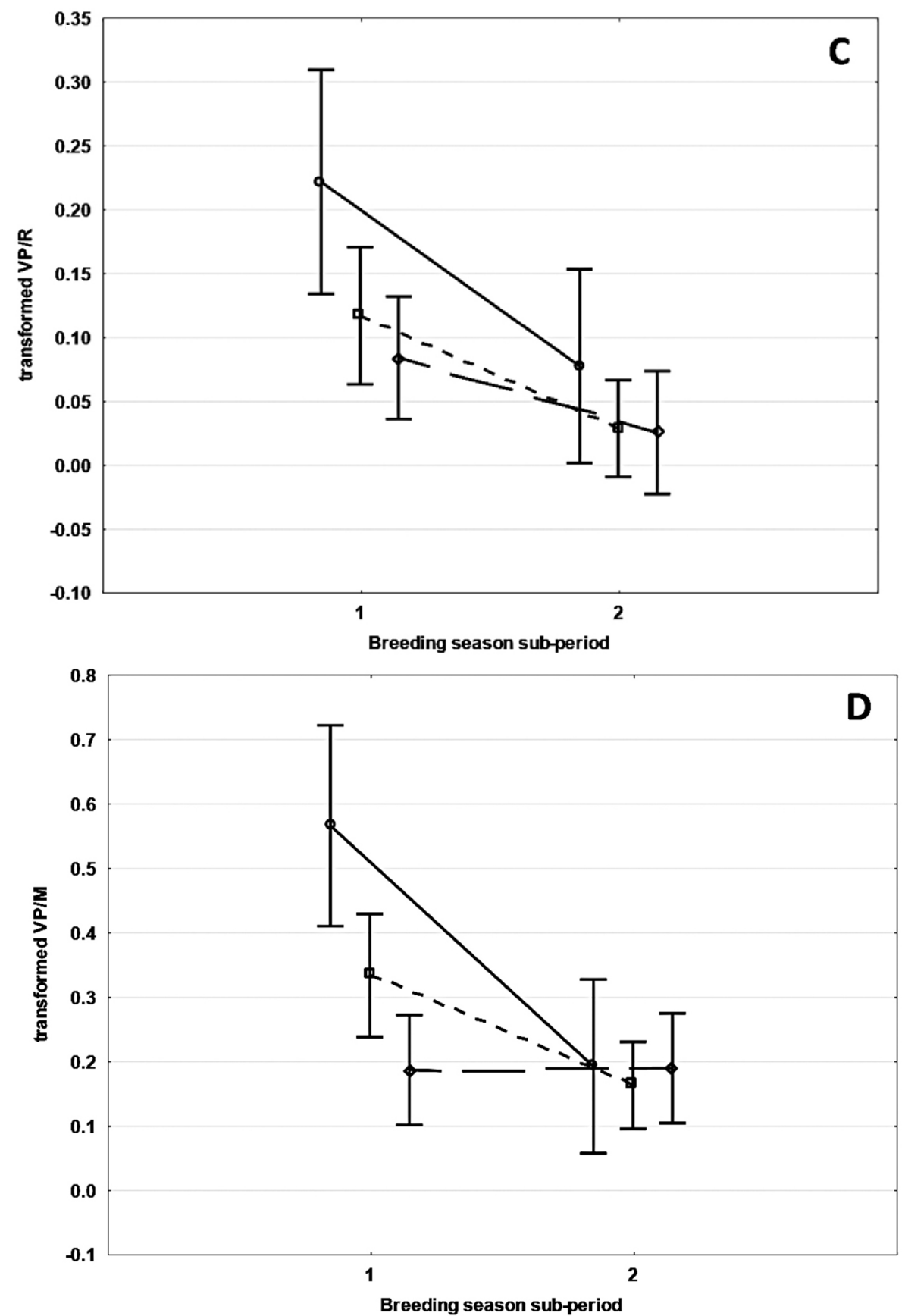

Fig. 2. Development of semen characteristics showing significant differences in A) percentage of spermatozoa with progressive motility (PR), B) percentage of rapid velocity spermatozoa (Velocity/R >100 $\mu \mathrm{m} / \mathrm{s}$ ), C) percentage of rapid progressive spermatozoa (VP/R), D) percentage of medium progressive spermatozoa (VP/M). Explanation: full line $=$ Aquila heliaca , dotted line $=$ Accipiter gentilis, dashed line $=$ Falco peregrinus . Vertical bars denote 0.95 confidence intervals. 
Table 3. Fresh semen characteristics in three bird of prey species.

\begin{tabular}{|c|c|c|c|c|c|c|c|c|}
\hline Variable & Valid N & Mean & $\mathrm{SD}$ & Median & Lower quartile & Upper quartile & Min & Max \\
\hline \multicolumn{9}{|c|}{ Aquila heliaca } \\
\hline Concentration & 7 & 140.78 & 68.22 & 110.08 & 91.82 & 205.89 & 74.14 & 221.99 \\
\hline PR & 7 & 4.43 & 1.95 & 4.68 & 3.06 & 5.37 & 2.03 & 7.01 \\
\hline NP & 7 & 27.64 & 14.07 & 30.54 & 13.84 & 34.02 & 13.42 & 46.36 \\
\hline IM & 7 & 68.34 & 15.44 & 64.78 & 63.95 & 80.79 & 46.64 & 85.52 \\
\hline Motile & 7 & 32.06 & 14.90 & 35.22 & 19.21 & 36.05 & 16.48 & 53.36 \\
\hline Velocity/R & 7 & 1.39 & 1.66 & 0.55 & 0.47 & 1.28 & 0.36 & 4.28 \\
\hline Velocity/M & 7 & 6.63 & 2.07 & 7.23 & 5.91 & 7.30 & 3.56 & 9.16 \\
\hline Velocity/S & 7 & 24.05 & 15.84 & 28.76 & 7.91 & 32.14 & 7.70 & 43.74 \\
\hline $\mathrm{VP} / \mathrm{R}$ & 7 & 0.80 & 1.30 & 0.26 & 0.15 & 0.37 & 0.09 & 3.11 \\
\hline $\mathrm{VP} / \mathrm{M}$ & 7 & 3.64 & 2.06 & 2.81 & 2.26 & 4.31 & 1.88 & 6.92 \\
\hline $\mathrm{VP} / \mathrm{NP}$ & 7 & 27.64 & 14.07 & 30.54 & 13.84 & 34.02 & 13.42 & 46.36 \\
\hline \multicolumn{9}{|c|}{ Accipiter gentilis } \\
\hline Concentration & 22 & 110.17 & 63.21 & 96.19 & 56.55 & 170.24 & 24.59 & 224.53 \\
\hline PR & 22 & 7.13 & 9.11 & 2.65 & 1.30 & 8.80 & 0.46 & 31.93 \\
\hline NP & 22 & 44.44 & 19.06 & 39.47 & 31.50 & 56.71 & 10.43 & 82.14 \\
\hline $\mathrm{IM}$ & 22 & 48.42 & 22.82 & 58.13 & 27.79 & 63.89 & 11.49 & 89.02 \\
\hline Motile & 22 & 51.58 & 22.82 & 41.88 & 36.12 & 72.21 & 10.98 & 88.51 \\
\hline Velocity/R & 22 & 1.42 & 2.24 & 0.37 & 0.19 & 1.33 & 0.00 & 7.37 \\
\hline Velocity/M & 22 & 9.33 & 9.61 & 3.77 & 2.38 & 16.92 & 0.81 & 35.45 \\
\hline Velocity/S & 22 & 40.41 & 17.97 & 37.81 & 29.66 & 53.81 & 10.16 & 74.10 \\
\hline $\mathrm{VP} / \mathrm{R}$ & 22 & 0.79 & 1.68 & 0.14 & 0.00 & 0.50 & 0.00 & 6.84 \\
\hline $\mathrm{VP} / \mathrm{M}$ & 22 & 6.34 & 7.81 & 2.42 & 1.27 & 8.23 & 0.46 & 28.34 \\
\hline $\mathrm{VP} / \mathrm{NP}$ & 22 & 44.57 & 19.14 & 39.47 & 31.50 & 58.21 & 10.43 & 82.14 \\
\hline \multicolumn{9}{|c|}{ Falco peregrinus } \\
\hline Concentration & 18 & 143.84 & 91.00 & 134.43 & 78.09 & 202.71 & 14.76 & 364.44 \\
\hline PR & 18 & 5.96 & 4.46 & 5.12 & 3.73 & 8.31 & 0.00 & 14.86 \\
\hline NP & 18 & 35.29 & 17.44 & 32.08 & 19.39 & 47.21 & 10.28 & 65.34 \\
\hline IM & 18 & 59.37 & 18.56 & 60.41 & 46.73 & 75.29 & 30.67 & 88.21 \\
\hline Motile & 18 & 41.20 & 18.75 & 40.85 & 24.71 & 53.27 & 11.79 & 69.63 \\
\hline Velocity/R & 18 & 2.01 & 3.62 & 0.46 & 0.00 & 1.56 & 0.00 & 11.75 \\
\hline Velocity/M & 18 & 7.82 & 5.13 & 7.01 & 4.70 & 12.29 & 0.00 & 16.34 \\
\hline Velocity/S & 18 & 31.09 & 16.19 & 25.04 & 16.86 & 42.96 & 9.93 & 61.96 \\
\hline $\mathrm{VP} / \mathrm{R}$ & 18 & 1.08 & 2.22 & 0.06 & 0.00 & 0.46 & 0.00 & 7.33 \\
\hline $\mathrm{VP} / \mathrm{M}$ & 18 & 4.85 & 2.94 & 4.80 & 3.68 & 7.17 & 0.00 & 9.34 \\
\hline $\mathrm{VP} / \mathrm{NP}$ & 18 & 35.27 & 17.41 & 32.08 & 19.39 & 47.21 & 10.28 & 65.34 \\
\hline
\end{tabular}

$\mathrm{SD}=$ standard deviation; Concentration $=$ semen concentration $\left(\times 10^{6} / \mathrm{ml}\right) ; \mathrm{PR}=$ percentage of spermatozoa with progressive motility; NP = percentage of spermatozoa with non-progressive motility; IM = percentage of immotile spermatozoa; Motile = percentage of motile spermatozoa; Velocity $/ \mathrm{R}=$ percentage of rapid velocity spermatozoa $(>100 \mu \mathrm{m} / \mathrm{s})$; Velocity/M = percentage of medium velocity spermatozoa $(50 \mu \mathrm{m} / \mathrm{s})$; Velocity/S = percentage of slow velocity spermatozoa $(<10 \mu \mathrm{m} / \mathrm{s}), \mathrm{VP} / \mathrm{R}=$ percentage of rapid progressive spermatozoa; VP/M $=$ percentage of medium progressive spermatozoa and $\mathrm{VP} / \mathrm{NP}=$ percentage of non-progressive spermatozoa. 
A total of 20 eggs were laid by the eight peregrine falcon females following AI with semen collected during this study, showing a 70\% fertilization success rate. Levels of total motility and percentage of spermatozoa with progressive motility were higher in semen samples resulting in egg fertilization $(\mathrm{n}=20, P<0.01)$. Minimum semen characteristics associated with egg fertilization included a semen concentration of $115.12 \times 10^{6} / \mathrm{ml}, 33.52 \%$ total motility, $1.92 \%$ spermatozoa with progressive motility and $0.17 \%$ spermatozoa with rapid motility (Table 3 ).

\section{Discussion}

In this study, we compared semen quality in captive accipitrid and falconid birds of prey and, in so doing, provided baseline data on concentration and spermatozoa kinematics of fresh semen for future studies. Our data suggest that the eastern imperial eagle makes a high-quality semen investment by producing semen of high concentration with a high percentage of progressive spermatozoa at the start of the breeding season, with semen concentration and progressive movement-associated parameters decreasing in the second part of the breeding season. The northern goshawk compensates for a drop in motilityassociated parameters with semen concentration increasing over time. In comparison, the peregrine falcon maintains semen production with little or no quantitative alteration throughout the course of the breeding season. When used for AI, fertilization success using semen collected from donor male birds was directly related with the total motility and percentage of spermatozoa with progressive motility.

Progressive motility of spermatozoa (alongside semen concentration) is a good indicator of male fertility and both general state of health and health of the reproductive tract (Vyvial et al. 2019). Reduced sperm motility parameters are frequently associated with inflammation and severe infection (Björndahl 2010; Vitula et al. 2011). Likewise, many natural and anthropogenic toxins can, singly or in combination, interfere with normal spermatogenesis, resulting in testicular toxicity and impaired fertility (Damkova et al. 2011; Osickova et al. 2012; Pikula et al. 2013). In general, reproductive system disorders may result from nutritional deficiency, testicular neoplasia and systemic or reproductive tract infections including, for example, Salmonella spp., Escherichia coli, Mycobacterium spp., Chlamydia psittaci, Aspergillus spp. (Samour 2016).

Naturally reproducing, healthy avian populations generally have a fertility rate of $80 \%$ or higher (Damkova et al. 2009; Hruba et al. 2019). Interestingly, in the present study, $70 \%$ of eggs were fertilized in inseminated falcon females, despite the observed motilityassociated parameters being lower than those recommended for use in AI (Bailey and Lierz 2017). Our data showed that while semen parameters in birds of prey display a rather high level of variation, minimum quality values are required to fertilize the egg (Blanco et al. 2002).

Birds of prey lack a copulatory organ and semen is transferred via a so-called 'cloacal kiss'. During AI, however, the insemination dose is inserted into the pars uterina of the oviduct, i.e. closer to the site of fertilization in the upper oviduct (Blanco et al. 2002; Kharayat et al. 2016), thereby increasing the chance of successful fertilization. A further factor that may have contributed to the relatively high AI fertility rate observed in this study is the regularity of insemination (Kharayat et al. 2016). When an egg is laid, ovulation of the next egg in the clutch occurs within an hour (McWilliams et al. 2016); as such, AI should be performed no later than $2 \mathrm{~h}$ after each oviposition.

Female birds are known to lay many fertile eggs after a single mating as they are able to store viable sperm within oviduct storage tubules for days or even weeks (Blesbois and Brillard 2007). As human inseminators have no cues to predict and/or detect the brief fertile period when the first egg in the clutch is produced, it often goes unrecognized 
and is consequently wasted as infertile. To ensure fertilization of the first egg, naturally breeding birds of prey that lay a single egg or a small clutch may need to invest into higher quality semen at the start of the breeding season, as in the eastern imperial eagle, and/or copulate frequently for an extended pre-laying period, as in the northern goshawk (Møller 1987; del Hoyo et al. 1994; Margalida and Bertran 2010). A frequent copulation strategy also ensures paternity (Mouge ot 2004). In some bird species, synchrony with the females' fertility and egg laying period is achieved through responding to a courting male (McWilliams et al. 2016).

Birds of prey are generally solitary territorial breeders with monogamy as the predominant mating system (del Hoyo et al. 1994); however, extra-pair copulations (Mougeot 2004) do occur in polygynous falconid birds. In polyandrous birds (Wedell et al. 2002), however, it is not the mating system that determines semen quality parameters but sperm competition. As such, AI using semen pooled from several male birds could result in unnatural sperm competition.

While egg development represents a major reproductive effort in a laying hen, semen production represents the reproductive cost to males (Wedell et al. 2002). When males copulate at high frequency in the breeding season, available sperm must be proportionately allocated for each mating event and/or sperm maturation has to be efficient (Wedell et al. 2002). Consequently, semen may be collected from male birds of prey on a daily basis. However, stressful handling of donor birds has to be limited.

To conclude, our study showed that sperm quality is critical for successful reproduction in birds of prey. With some limitations, AI using fresh semen $(<2 \mathrm{~h}$ after collection) can result in egg fertilization rates almost as successful as natural mating. As sperm donor selection is done by humans with the specific aim of passing on attributes to their progeny, we highly recommend that a sperm quality check is undertaken prior to AI.

\section{Acknowledgements}

This study was supported through the Internal Grant Agency of the University of Veterinary and Pharmaceutical Sciences Brno (Grant No. 232/2017/FVHE). We are grateful to Dr. Kevin Roche for correction and improvement of the English text. The authors also thank Czech Falconry Club members Karel Světlík, Jiří Nejedlý, Jiří Galát, Vlastimil Voráček and Eduard Školoud, along with MVDr. Monika Krajčovičová, Roman Gabura and Filip Weis from the Slovak Falconry Club, for their help with this study.

\section{References}

Bailey TA, Lierz M 2017: Veterinary Aspects of Bird of Prey Reproduction. Vet Clin Exot Anim 20: 455-483

Björndahl L 2010: The usefulness and significance of assessing rapidly progressive spermatozoa. Asian J Androl 12: $33-35$

Blanco JM, Gee GF, Wildt DE, Donoghue AM 2002: Producing progeny from endangered birds of prey: treatment of urine-contaminated semen and a novel intramagnal insemination approach. J Zoo Wildlife Med 33: 1-7

Blesbois E, Brillard JP 2007: Specific features of in vivo and in vitro sperm storage in birds. Animal 1: $1472-1481$

Damkova V, Sedlackova J, Bandouchova H, Peckova L, Vitula F, Hilscherova K, Paskova V, Kohoutek J, Pohanka M, Pikula J 2009: Effects of cyanobacterial biomass on avian reproduction: a Japanese quail model. Neuroendocrinol Lett 30: 205-210

Damkova V, Paskova V, Sedlackova J, Bandouchova H, Hilscherova K, Novotny L, Peckova L, Vitula F, Pohanka M, Pikula J 2011: Testicular toxicity of cyanobacterial biomass in Japanese quails. Harmful Algae 10: 612-618

del Hoyo J, Elliott A, Sargatal J 1994: Handbook of the birds of the world. New World vultures to Guineafowl, vol 2. Lynx Editions, Barcelona, 640 p.

Fickel J, Wagener A, Ludwig A 2007: Semen cryopreservation and the conservation of endangered species. Eur J Wildl Res 53: 81-89

Fleming LV, Douse AF, Williams NP 2011: Captive breeding of peregrine and other falcons in Great Britain and implications for conservation of wild populations. Endanger Species Res 14: 243-257

Fry DM 1995: Reproductive effects in birds exposed to pesticides and industrial chemicals. Environ Health Persp 103: $165-171$

Gee GF, Bertschinger H, Donoghue AM, Blanco J, Soley J 2004: Reproduction in nondomestic birds: Physiology, semen collection, artificial insemination and cryopreservation. Avian Poult Biol Rev 15: 47-101 
Hruba H, Abdelsalam EEE, Anisimov N, Bandouchova H, Havelkova B, Heger T, Kanova M, Kovacova V, Nemcova M, Piacek V, Sedlackova J, Vitula F, Pikula J 2019: Reproductive toxicity of fluoroquinolones in birds. BMC Vet Res 15: 209

Jones CG, Heck W, Lewis RE, Mungroo Y, Slade G, Cade T 1995: The restoration of the Mauritius Kestrel Falco punctatus population. Ibis 137: 173-180

Kharayat NS, Chaudhary GR, Katiyar R, Balmurugan B, Patel M, Uniyal S, Raza M, Mishra GK 2016: Significance of artificial insemination in poultry. J Vet Sci Technol 5: 1-5

Long JA 2006: Avian semen cryopreservation: what are the biological challenges? Poultry Sci 85: 232-236

Margalida A, Bertran J 2010: Copulatory behaviour in the colonial Eurasian Griffon vulture Gyps fulvus. J Ethol 28: 179

McWilliams S, Adkins-Regan E, Vleck C 2016: Bird Physiology. In: Lovette IJ, Fitzpatrick JW (Eds): The Cornell Lab of Ornithology Handbook of Bird Biology. Wiley, Oxford, UK, pp. 215-262

Meretsky VJ, Snyder NFR, Beissinger SR, Clendenen DA, Wiley JW 2000: Demography of the California condor: implications for reestablishment. Conserv Biol 14: 957-967

Møller AP 1987: Copulation behaviour in the Goshawk Accipiter gentilis. Anim Behav 35: 755-763

Mougeot F 2004: Breeding density, cuckoldry risk and copulation behaviour during the fertile period in raptors: a comparative analysis. Anim Behav 67: 1067-1076

Osickova J, Skochova H, Ondracek K, Kral J, Damkova V, Peckova L, Pohanka M, Vitula F, Bandouchova H, Pikula J 2012: Risk of single and combined exposure of birds to non-steroidal anti-inflammatory drugs and lead. Neuroendocrinol Lett 33: 145-150

Pikula J, Hajkova P, Bandouchova H, Bednarova I, Adam V, Beklova M, Kral J, Ondracek K, Osickova J, Pohanka M, Sedlackova J, Skochova H, Sobotka J, Treml F, Kizek R 2013: Lead toxicosis of captive vultures: case description and responses to chelation therapy. BMC Vet Res 9: 11

Samour JH 2004: Semen collection, spermatozoa cryopreservation, and artificial insemination in nondomestic birds. J Avian Med Surg 18: 219-223

Samour J 2016: Avian medicine. Elsevier, St. Louis, Missouri, USA, 699 p.

Snyder NFR, Derrickson SR, Beissinger SR, Wiley JW, Smith TB, Toone WD, Miller B 1996: Limitations of Captive Breeding in Endangered Species Recovery. Conserv Biol 10: 338-348

Vitula F, Peckova L, Bandouchova H, Pohanka M, Novotny L, Jira D, Kral J, Ondracek K, Osickova J, Zendulkova D, Rosenbergova K, Treml F, Pikula J 2011: Mycoplasma gallisepticum infection in the grey partridge Perdix perdix: outbreak description, histopathology, biochemistry and antioxidant parameters. BMC Vet Res 7: 34

Vyvial M, Horáčková E, Sedlinská M, Jánová E, Krisová S, Mráčková M 2019: Determination of selected components in seminal plasma of donkey stallions and their correlation to semen quality parameters. Acta Vet Brno 88: 377-384

Wedell N, Gage MJG, Parker GA 2002: Sperm competition, male prudence and sperm-limited females. Trends Ecol Evol 17: 313-320 